\title{
Infrared thermography study of heat sources caused by bacterial adhesion
}

\author{
by A. Yu. Fedorova*, A. V. Krivoruchko**, O. A. Plekhov*, O. B. Naimark, I. B. Ivshina** \\ *Institute of Continuous Media Mechanics UB RAS, 614013, Perm, Academ. Koroleva Street, 1, e-mail: \\ fedorova@icmm.ru \\ **Institute of Ecology and Genetics of Microorganisms UB RAS, 614081, Perm, Golev Street, 13
}

\begin{abstract}
This work is devoted to the development of original method based on high resolution infrared thermography for investigation of weak heat sources associated with bacterial adhesion. In this work, theoretical description of the problem and results of studies on heat flow generated by adhesion of Rhodococcus actinobacteria to polystyrene microplates are presented. According to the experimental conditions, mathematical model of the heat production dynamics was developed. This model allows us to model an effect of boundary conditions and inhomogeneity of the temperature distribution on formation of heat flow patterns. Inverse problem of thermal conductivity was solved.
\end{abstract}

Key words: infrared thermography, bacterial adhesion, Rhodococcus actinobacteria, polystyrene, exothermic process, heat capacity of weak heat sources.

\section{Introduction}

Bacterial adhesion is a complex process of interaction between bacterial cells and different surfaces. Colonization of solid substrates by microbial cells, hydrophobic compound biodegradation, appearance and growth of microbial biofilms, bacteriocenose formation in rizo- and phyllosphere, and invasion of pathogenic bacteria into the tissues of multicellular organisms are proportionally associated with bacterial adhesion. Possible consequences of bacterial adhesion are catheter-associated infections, microbial contamination on medical instruments and equipment of food industry, biological corrosion of metals, bacterial fouling on underwater constructions and bottoms of water vessels $[1,2]$. Along with this, bacterial adhesion is important for biotechnological processes because it is a key stage at development of immobilized biocatalysts, biofilters, biosensor devices, immobilized cell reactors [1-3]. Therefore, search for ways to manage (enhance or inhibit) bacterial adhesion is an actual problem. Solution of this practical task requires fundamental knowledge about mechanisms of bacterial cell adhesion, physicochemical and biological factors that influence on adhesion, basic kinetic and thermodynamic laws of adhesion process.

Bacterial adhesion is an exothermic process; this fact allows us to use thermal methods for its studying. Herewith, bacterial cells which contact with solid surfaces are weak heat sources $\left(2-4^{\star} 10^{-3} \mathrm{~J} / \mathrm{m}^{2}\right.$ heat is produced at bacterial adhesion) [4]. Therefore, we used an infrared camera with a high resolution $(\leq 0,025 \mathrm{~K})$ for registration of heat flow generated by bacterial adhesion. Temperature and heat data obtained by infrared thermography can be used to calculate kinetic and thermodynamic parameters of bacterial adhesion, determine the temperature evolution law in a medium with bacterial cells and a carrier, measure the adhesion power and establish the spatial distribution of weak heat sources associated with bacterial adhesion. In the published literature, thermal imaging methods are not used to study adhesion of bacteria to solid surfaces.

The purpose is to develop a new experimental method based on infrared thermography for the study of heat flow generated by bacterial adhesion (particularly by adhesion of Rhodococcus actinobacteria to polystyrene microplates).

In contrast to traditional calorimetrical or contact angle methods, infrared thermography does not require preliminary preparation of samples and not depend on sample sizes. On the other hand, there are significant problems with the influence of random heat sources and the accuracy of temperature measurement on infrared thermography results. The perspective for further development and application of this method requires a comprehensive solution for these problems. It is possible, for example, in comparative studies with thermography and calorimetry methods. It will be a logical continuation of this work.

\section{Thermodynamic description of heat flow generated by bacterial adhesion}

The process of bacterial adhesion usually occurs in water. Temperature changes in an aqueous medium containing bacterial cells and a carrier are described in polar coordinates by the next expression: 


$$
\rho c \frac{\partial T}{\partial t}=\lambda\left(\frac{1}{r} \frac{\partial}{\partial r}\left(r \frac{\partial T}{\partial r}\right)+\frac{1}{r^{2}} \frac{\partial^{2} T}{\partial \varphi^{2}}\right)+Q_{1}(t)+Q_{2}(t)
$$

where $T$ - temperature; $t$ - time, s; $\varphi, r$ - polar coordinates, $Q_{1}$ - the specific heat power of heat source associated with metabolism of bacterial cells; $Q_{2}$ the specific heat power of heat source associated with adhesion of bacterial cells; $\rho-$ density of the medium (for aqueous media $\rho=1000 \mathrm{~kg} / \mathrm{m}^{3}$ ); $c$ - heat capacity of the medium (for aqueous media $c=4183$ $J /(\mathrm{kg} \cdot \mathrm{K})$ ); $\lambda$ - thermal conductivity of the medium (for aqueous media $\lambda=4.6 \mathrm{~W} /(\mathrm{m} \cdot \mathrm{K})$ ).

We introduce the average temperature of an aqueous medium in an area with a characteristic size $r_{0}$ :

$$
\theta(t)=\frac{1}{\pi r_{0}^{2}} \int_{0}^{2 \pi r_{0}} r\left(T(r, \varphi, t)-T_{c p}\right) d r d \varphi
$$

where $T_{c p}$ - room temperature, $r_{0}$ - the radius of the investigated area.

We write the boundary conditions as follows:

$$
-\lambda \frac{\partial T\left(r_{0}, \varphi, t\right)}{\partial r}=\beta \theta(t)
$$

where $\beta$ - the heat transfer coefficient.

Assuming that the temperature $T$ does not depend on the rotation angle $\varphi\left(\frac{\partial T}{\partial \varphi}\right)=0$, the derivative of the temperature along the radius is different from zero only on the boundary of the area, and the functions $Q_{1}(t)$ and $Q_{2}(t)$ are not changed in the $r$ and $\varphi$ coordinates. Using the expressions (1), (2) (3), we obtain the equation for average temperature changes:

$$
\rho c \frac{\partial \theta(t)}{\partial t}=-\frac{2}{r_{0}} \beta \theta(t)+Q_{1}(t)+Q_{2}(t)
$$

We introduce the dimensionless temperature:

$$
\bar{\theta}(t)=\frac{\theta(t)-T_{1}}{T_{1}}
$$

where $T_{1}-$ the initial temperature of a medium.

We assume that

$$
Q(t)=Q_{1}(t)+Q_{2}(t)
$$

then the equation (4) becomes:

$$
\frac{\partial \bar{\theta}(t)}{\partial t}+\frac{2 \beta}{r_{0} \rho c} \bar{\theta}(t)=\frac{1}{T_{1} \rho c} Q(t)-\frac{2 \beta}{r_{0} \rho c} .
$$

We solve the equation (5) by the method of an arbitrary constant variation and obtain:

$$
\bar{\theta}(t)=e^{-\frac{2 \beta}{r_{0} \rho c} t} \int_{0}^{t} e^{\frac{2 \beta}{r_{0} \rho c}} t\left(\frac{1}{T_{1} \rho c} Q(t)-\frac{2 \beta}{r_{0} \rho c}\right) d t .
$$

The equation (6) is a description of the dimensionless temperature in an aqueous medium with a heat source having the specific power of equal $Q(t)$ depending on time.

To account the background temperature changes, not related to the presence of bacterial cells, we use an aqueous medium with a carrier without cells (abiotic control). It is natural to assume that there is no source of heat and $Q(t)=0$. The expression for the abiotic control temperature changes is: 


$$
\bar{\theta}_{C}(t)=e^{-\frac{2 \beta}{r_{0} \rho c} t} \int_{0}^{t}-\frac{2 \beta}{r_{0} \rho c} e^{\frac{2 \beta}{r_{0} \rho c} t} d t .
$$

We substitute (7) in (6) and obtain the expression to determine $Q(t)$ :

$$
Q(t)=T_{1} \rho c \frac{\partial}{\partial t}\left(\bar{\theta}(t)-\bar{\theta}_{C}(t)\right)+\frac{2 \beta T_{1}}{r_{0}}\left(\bar{\theta}(t)-\bar{\theta}_{C}(t)\right) .
$$

In dimensional variables, the last ratio looks as:

$$
Q(t)=\rho c \frac{\partial}{\partial t}\left(\left(\theta(t)-T_{1}\right)-\left(\theta_{C}(t)-T_{1_{C}}\right)\right)+\frac{2 \beta}{r_{0}}\left(\left(\theta(t)-T_{1}\right)-\left(\theta_{C}(t)-T_{1_{C}}\right)\right),
$$

where $T_{1 C}$ - the temperature of the abiotic control at the start of adhesion; $T_{1}$ - temperature of a medium with cells and a carrier at the start of adhesion.

We introduce the following notation:

$$
\begin{aligned}
& \theta^{\prime}(t)=\theta(t)-T_{1}, \\
& \theta_{C}^{\prime}(t)=\theta_{C}(t)-T_{1_{C}},
\end{aligned}
$$

Then the final formula for determination of the specific heat power of a weak heat source associated with bacterial adhesion was:

$$
Q(t)=\rho c \frac{\partial}{\partial t}\left(\theta^{\prime}(t)-\theta_{C}^{\prime}(t)\right)+\frac{2 \beta}{r_{0}}\left(\theta^{\prime}(t)-\theta_{C}^{\prime}(t)\right),
$$

where $\theta^{\prime}(t)$ - a temperature change in an aqueous medium with cells and a carrier; $\theta^{\prime} c(t)$ - a temperature change of the control.

\section{Microorganisms, carriers and the experimental conditions}

In this work we used Rodococcus ruber IEGM 342 strain from the Regional Specialized Collection of Alkanotrophic Microorganisms (acronym IEGM, WFCC \# 768, www.iegm.ru/iegmcol). This strain is a representative of ecology significant species of actinobacteria, one of which biological feature is the ability to assimilate a wide range of hydrocarbon compounds ( $n$-alkanes $\mathrm{C}_{3}-\mathrm{C}_{37}$, branched and cyclic paraffins, benzene and its structural analogues, polycyclic aromatic hydrocarbons, olefins, halogenated hydrocarbons). R. ruber strains are used in biotechnology as biocatalysts for fine organic synthesis, biodestructors for oil pollutants, biological indicators for hydrocarbon deposits, producers for proteins, biosurfactants, and metabolically active compounds (vitamins, amino acids, organic acids) [5-7]. The $R$. ruber IEGM 342 strain was selected for experiments because of its high (47\%) adhesive activity towards solid surfaces, particularly a model surface as polystyrene. This is a relevant condition for detection of total thermal radiation in infrared thermography experiments without any losses. Rhodococci were grown in Erlenmeyer flasks containing $100 \mathrm{ml}$ of nutrient broth (FGUN State Research Center for Applied Microbiology and Biotechnology, Obolensk) in an orbital shaker $(150 \mathrm{rpm})$ at $28^{\circ} \mathrm{C}$ for 28 hours. Then cells were washed twice with a phosphate buffer $(\mathrm{pH} 7.0)$ and resuspended in the same buffer to achieve a cell concentration of $10^{9}-10^{10}$ colony forming units (CFU)/ml. The composition of the buffer included, g/l: $\mathrm{Na}_{2} \mathrm{HPO}_{4}-3.53, \mathrm{KH}_{2} \mathrm{PO}_{4}-3.39$ [8].

The 96-wells polystyrene microplates (Medpolymer, Russia) were used as a carrier for Rhodococcus cells. Two types of microplate wells, hydrophobized with Rhodococcus biosurfactant and native (non-hydrophobized) were used in experiments. It allows to obtain comparative data about the heat flow and weak heat sources' power during cell adhesion to surfaces with different physicochemical properties. For hydrophobization, glycolipid biosurfactant produced by Rhodococcus actinobacteria at assimilation of liquid hydrocarbons was used. The biosurfactant was isolated from $R$. ruber IEGM 231 cells grown in the presence of $n$-dodecane with methyl tertiary butyl ether according to the procedure [11] and dissolved in isopropanol (reagent grade, Inc. "The base number 1 chemical reagents", Old Kupavna) at a concentration of $0.1 \mathrm{mg} / \mathrm{ml}$. The isopropanol solution of the Rhodococcus biosurfactant was added into microplate wells in a volume of 100 $\mathrm{ml}$ per well and the plates were left in air for 2 days to evaporate isopropanol and obtain the biosurfactant coating on a surface of wells.

The cell suspension was added into non-sterile polystyrene microplates in a volume of $0.1 \mathrm{ml}=10^{-7} \mathrm{~m}^{3}$ per well. The wells with non-inoculated phosphate buffer of the same volume were used as a control. The plates were placed in a thermal insulation box combined with an infrared camera. In this paper we used an infrared camera CEDIP Silver 450M (CEDIP Infrared Systems, France) with a high temperature $(0.025 \mathrm{~K})$ and spatial $\left(10^{-4} \mathrm{~m}\right)$ sensitivity. The wall thickness of 
the box was more than $30 \mathrm{~mm}$ that excluded the effect of ambient air convection and significantly smoothed out fluctuations in temperature laboratory facilities. The box was wrapped in a layer of foil to eliminate the influence of external electromagnetic radiation. This experimental setup allows determination of small (about $0.1 \mathrm{~K}$ ) temperature changes during bacterial adhesion. To eliminate the effect of infrared ray reflection from the surface of a polystyrene microplate, the camera lens was rotated by an angle $\approx 10^{\circ}$ relative to the normal surface of a polystyrene microplate. The setup is shown in the Fig. 1. The experiment was carried out for 80 - 300 minutes. The duration of one measurement depended on the conditions and objectives of the experiment and was 10-15 min in the average. At computer analysis, the relative temperature changes were used to eliminate the influence of initial conditions related to the heterogeneity of a microplate emissivity. For this purpose, the first frame was subtracted from each frame sequence of infrared records made during experimental data processing. The experimental data were averaged over all wells for each variant of the experiment.

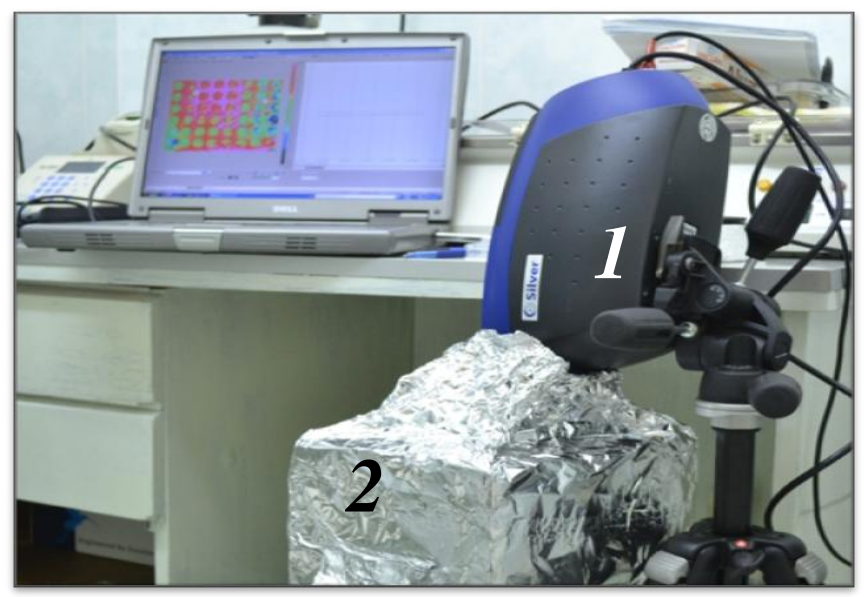

Fig. 1. The experimental setup: 1 - an infrared camera CEDIP Silver 450M; 2 - a thermal insulating box with 96-well polystyrene microplates.

At the end of the experiment, the effectiveness of adhesion was measured. For this, attached cells were washed 2 times with a phosphate buffer using a microplate washer Stat Fax ${ }^{\circledR} 2600$ (Awareness Technology Inc., USA), stained with $100 \mathrm{ml}$ of a $1 \%$ aqueous solution of crystal violet (reagent grade, Reahim, Russia) for 20 min, washed twice with a buffer, then the dye was extracted with $100 \mathrm{ml}$ acetone:ethanol in a ratio of 1:4 $(\mathrm{v} / \mathrm{v})$. The staining intensity was measured at $630 \mathrm{~nm}\left(\mathrm{~A}_{630}\right)$ with a microplate photometer Multiscan Ascent (Thermo electron corporation, Finland) [9]. Calibration between $A_{630}$ and number of colony forming units grown on nutrient agar plates was used for quantification of attached cells.

\section{Experimental determination of heat transfer conditions}

To determine the heat transfer coefficient in the experimental microplate wells, cooling behavior of the wells filled with the medium with or without rhodococcal cells was studied. The infrared camera recorded the temperature changes during the cooling. These temperature changes are given by:

$$
T(t)=T_{0} e^{\frac{2 \beta}{r_{0} \rho c} t}-T_{\text {bound }},
$$

The heat transfer coefficients were determined using (9). It was establish that the order of the heat transfer coefficient is the same for wells with and without cells. Further, the heat transfer coefficient was assumed as $\beta=490$ $\mathrm{J} /\left(\mathrm{m}^{2} \cdot \mathrm{K} \cdot \mathrm{sec}\right)$.

The accuracy control of the measurements was established in experiments on cooling wells filled with $0.67 \mathrm{M}$ calcium chloride $\left(\mathrm{CaCl}_{2}\right)$. Dissolution of anhydrous $\mathrm{CaCl}_{2}$ in water is an exothermal process and results in releasing 72.77 $\mathrm{kJ}$ heat [10]. In our experiments, the heat effect was $67.91 \mathrm{~kJ}$ that is close to the theoretical value. 


\section{Experimental studies on heat flow generated by Rhodococcus cell adhesion to polystyrene microplates}

The next abbreviations are used further as $L h$ - Rhodococcus biosurfactant hydrophobized wells of a polystyrene microplate containing rhodococcal cell suspension, $L n$ - non-hydrophobized (native) wells of a polystyrene microplate containing rhodococcal cell suspension, $C$ - abiotic control (wells with a medium without cells). In the Table 1 , results of Rhodococcus cell adhesion to polystyrene microplates in native (non-hydrophobized) and hydrophobized wells are shown. Data of three independent experiments with cell concentrations of $10^{10} \mathrm{CFU} / \mathrm{ml}$ (the experiment 1 ) and $10^{9}$ $\mathrm{CFU} / \mathrm{ml}$ (the experiments 2,3$)$ are presented. The highest $\left(13.35 \times 10^{7}\right.$ cells $\left./ \mathrm{cm}^{2}\right)$ adhesion intensity was in hydrophobized wells with a $10^{10} \mathrm{CFU} / \mathrm{ml}$ suspension of Rhodococcus cells. In non-hydrophobized wells with same cell concentration, adhesion was in 1.7 times weaker. When a $10^{9} \mathrm{CFU} / \mathrm{ml}$ cell suspension was used, adhesive activity of rhodococci was the minimal as $2.38-2.51 \times 10^{7}$ cells $/ \mathrm{cm}^{2}$ and not statistically significant different for hydrophobized and non-hdrophoized wells.

Table. 1. Number of attached Rhodococcus cells on polystyrene microplates dependening on cell concentration and type of wells

\begin{tabular}{|c|c|c|c|}
\hline \multirow{3}{*}{$\begin{array}{c}10^{10} \mathrm{CFU} / \mathrm{ml} \text { cell concentration } \\
\text { (experiment } 1)\end{array}$} & Wells & $L h$ & $L n$ \\
\hline & $\begin{array}{l}\text { Mean, } \\
x 10^{7} \text { cells } / \mathrm{cm}^{2}\end{array}$ & 13.35 & 7.86 \\
\hline & Standard deviation & 2.00 & 1.60 \\
\hline \multirow{3}{*}{$\begin{array}{c}10^{9} \mathrm{CFU} / \mathrm{ml} \text { cell concentration } \\
\text { (experiments } 2,3)\end{array}$} & Wells & $L h$ & $L n$ \\
\hline & $\begin{array}{l}\text { Mean, } \\
x 10^{7} \text { cells } / \mathrm{cm}^{2}\end{array}$ & 2.38 & 2.51 \\
\hline & Standard deviation & 0.86 & 0.45 \\
\hline
\end{tabular}

We assumed that thermodynamic parameters of rhodococcal cell adhesion to polystyrene microplated registered by infrared thermography should be proportionally associated with a number of attached cells on a polystyrene surface, or intensity of adhesion process. In Fig. 2, plots for temperature and power heat at Rhodococcus cell adhesion independence on time for the experiment 1 (the initial cell concentration of $10^{10} \mathrm{CFU} / \mathrm{ml}$ ) are shown. Total heat values were determined from the graphs in Fig. 2 for each variant of the experiment. This value for $L h$ was:

$\mathrm{Q}=1.77 \mathrm{~J}$;

for $L n$ :

$\mathrm{Q}=1.13 \mathrm{~J}$;

As seen from the obtained values, heat quantities are in accordance with biological analysis results. The most intensive flow of heat was in hydrophobized polystyrene wells, in which maximum adhesion was recorded at biological analysis too. In the non-hydrophobized (native) wells, the heat flow was decreased in 1.6 times that is close to decline of attached cell number (see Table 1).

In the experiment 2 (the initial cell concentration of $10^{9} \mathrm{CFU} / \mathrm{ml}$ ), no statistically significant differences in temperature distributions in hydrophobized and non-hydrophobized wells (Fig. 3) were revealed that was in agreement with the biological analysis results (see Table 1). In addition, no any temperature differences between wells with cells and without them were detected within the first 80 minutes from the start of adhesion. We assume that up to this point, the experimental medium came in temperature equilibrium, which was not noticeable in the previous experiment at the background of the high heat flow. Within the next 30 minutes, barely perceptible heat flow changes being in accordance with the biological analysis results were registered. The total heat for $L h$ was:

$\mathrm{Q}=0.03 \mathrm{~J}$;

for $L n$ :

$\mathrm{Q}=0.04 \mathrm{~J}$. 


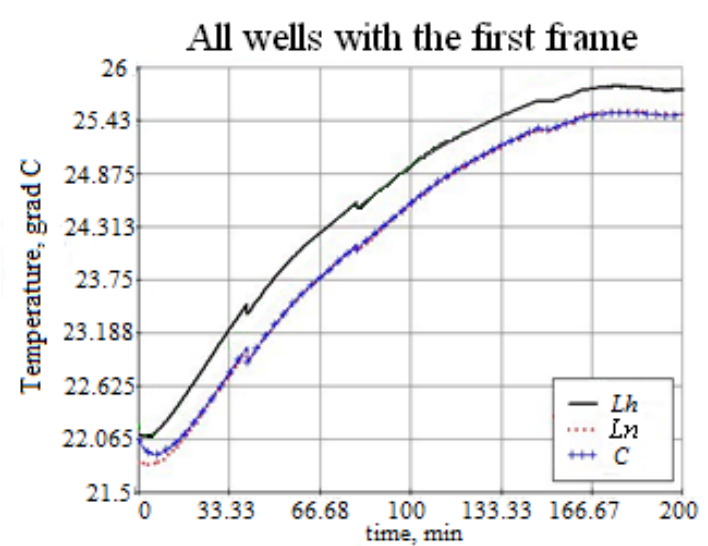

Hydrophobized wells

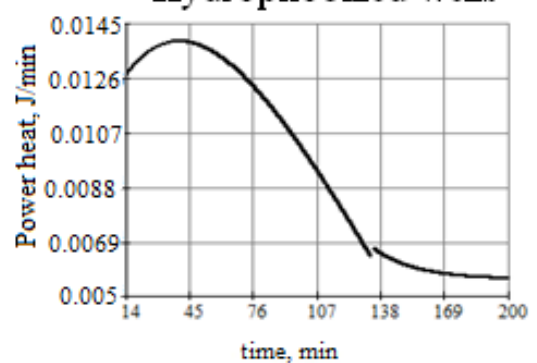

All wells without the first frame

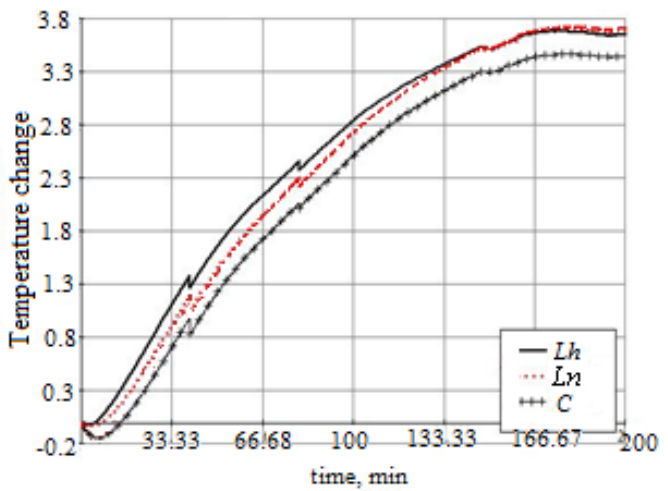

Non-hydrophobized (native) wells

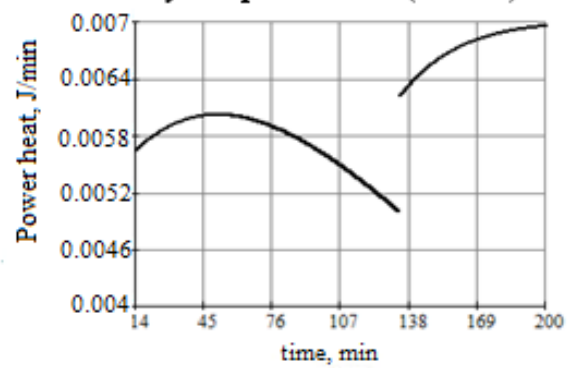

Fig. 2. Plots of temperature, temperature difference and heat power at Rhodococcus cell adhesion to polystyrene microplates depending on time. The experiment 1 results (the initial cell concentration of $10^{10} \mathrm{CFU} / \mathrm{ml}$ ).
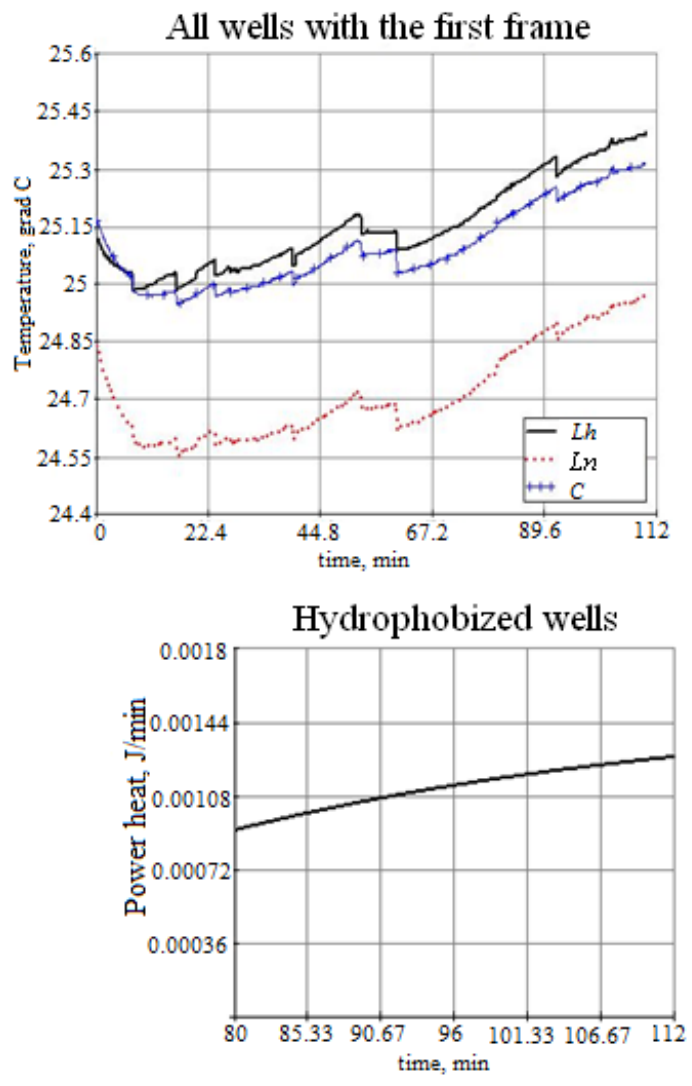

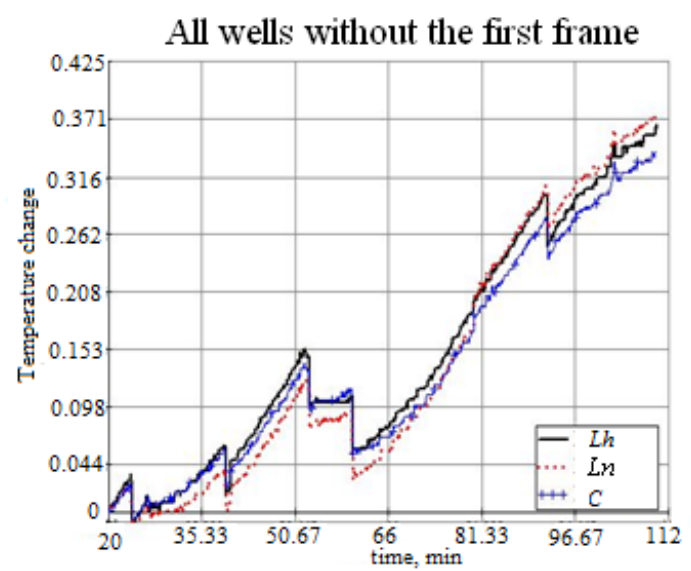

Non-hydrophobized (native) wells

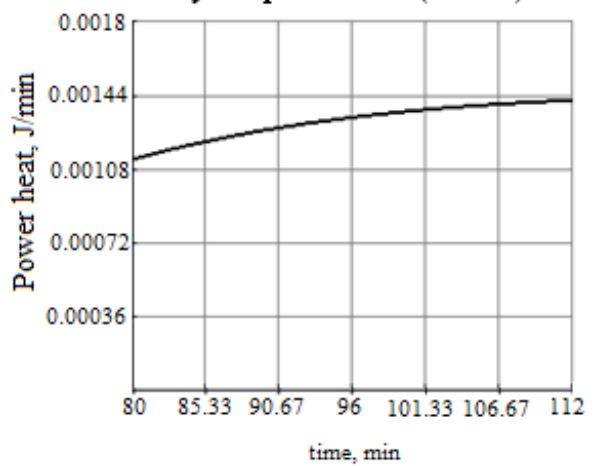

Fig. 3. Plots of temperature, temperature difference and heat power at Rhodococcus cell adhesion to polystyrene microplates depending on time. The experiment 2 results (the initial cell concentration of $10^{9} \mathrm{CFU} / \mathrm{ml}$ ). 
The experiment 3 repeated the experiment 2. Polystyrene microplates came to the temperature equilibrium within the first 160 minutes, after that actual temperature distribution was appeared (Fig. 4). The total heat after 160 minutes of adhesion in the experiment 3 for $L h$ was:

$$
\mathrm{Q}=0.074 \mathrm{~J} \text {; }
$$

for $L n$ :

$$
\mathrm{Q}=0.215 \mathrm{~J} \text {. }
$$

In this experiment, powers of weak heat sources associated with Rhodococcus cell adhesion to polystyrene microplates in hydrophobized and non-hydrophobized wells were in 2.5 and 5.4 times higher respectively than in the experiment 2. This fact is explained by different time taken for the calculations. Total heats generated by Rhodococcus cell adhesion to polystyrene microplates in the experiments 2 and 3 were in 5.0-5.9 times less than in the experiment 1 that is confirmed by the biological analysis data and related to the number of cells on a polystyrene.
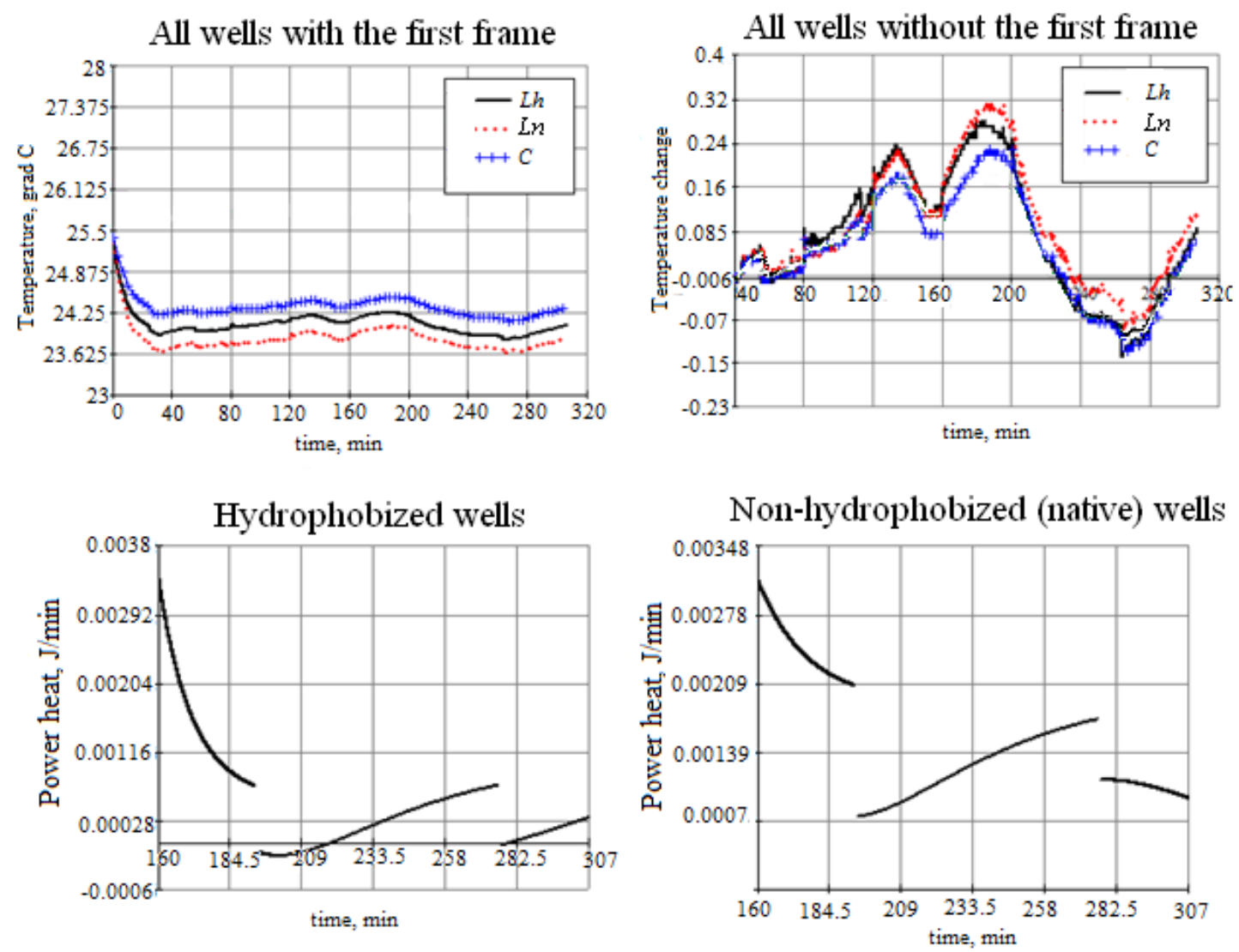

Fig. 4. Plots of temperature, temperature difference and heat power at Rhodococcus cell adhesion to polystyrene microplates depending on time. The experiment 3 results (the initial cell concentration of $10^{9} \mathrm{CFU} / \mathrm{ml}$ ).

Thus using infrared thermography to calculate the power of weak heat sources generated by bacterial adhesion, it is possible to obtain experimental results corresponding to independent microbiological analysis data that confirms the possibility for practical application of this method.

\section{Mathematical modeling of bacterial adhesion}

Experimentally investigated heat flow generated by Rhodococcus cell adhesion to polystyrene microplates was modeled in the ANSYS 12.1 software package by thermal analysis [12]. Backgrounds for specific power heat calculations are given in the Tables 2 and 3. Specific power values were found from the graphs shown in Fig. 2-4. 
Table 2. Constants for the numerical simulation of the heat production dynamics at the process of Rhodococcus cell adhesion to polystyrene microplates.

\begin{tabular}{|l|l|l|}
\hline Constant & Water & Polystyrene \\
\hline Density $\rho, \mathrm{kg} / \mathrm{m}^{3}$ & 1000 & 1050 \\
\hline Heat capacity $c, \mathrm{~J} /(\mathrm{K} \cdot \mathrm{kg})$ & 4183 & 1200 \\
\hline Thermal conductivity $\lambda, \mathrm{W} /(\mathrm{K} \cdot \mathrm{m})$ & 4.6 & 0.1 \\
\hline
\end{tabular}

Table 3. The initial specific power values $Q$ (t) of weak heat sources associated with Rhodococcus cell adhesion to polystyrene microplates taken for mathematical simulation.

\begin{tabular}{|c|c|c|c|}
\hline \multirow{2}{*}{ Experiment number } & \multicolumn{3}{|c|}{$\mathrm{Q}(\mathrm{t}), \mathrm{W} / \mathrm{m}^{3}$} \\
\cline { 2 - 4 } & $L h$ & $L n$ & $C$ \\
\hline 1 & 0.00923 & 0.00629 & 0 \\
\hline 2 & 0.00109 & 0.00127 & 0 \\
\hline 3 & 0.00157 & 0.00193 & 0 \\
\hline
\end{tabular}

The mathematical formulation for the heat conduction problem:

$$
\left\{\begin{array}{c}
\rho c \frac{\partial T}{\partial t}=\lambda \Delta T+q(x, y, t), 0<x<x_{0}, 0<y<y_{0}, t>0 \\
\left.\frac{\partial T}{\partial x}\right|_{x=x_{0}}=-\beta\left(T-T_{e \text { var age }}\right) \\
\left.\frac{\partial T}{\partial x}\right|_{x=0}=-\beta\left(T-T_{e \text { var age }}\right) \\
\left.\frac{\partial T}{\partial y}\right|_{y=y_{0}}=-\beta\left(T-T_{e \text { var age }}\right) \\
\left.\frac{\partial T}{\partial y}\right|_{y=0}=-\beta\left(T-T_{e \text { var age }}\right) \\
T(x, y, 0)=T_{e \text { var age }} .
\end{array}\right.
$$

The three experiments were simulated in the ANSYS 12.1. Relative positions of microplate wells at the modeling are shown in Fig. 5.

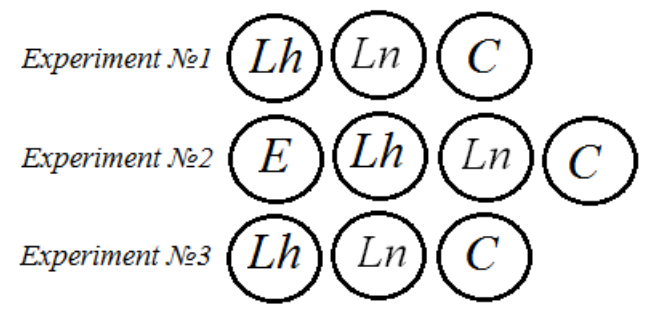

Fig. 5. Relative positions of polystyrene microplate wells under the ANSYS 12.1 analysis (E-empty wells).

The temperature distributions over the microplates revealed by the numerical simulation are shown in Fig. 6-8. 


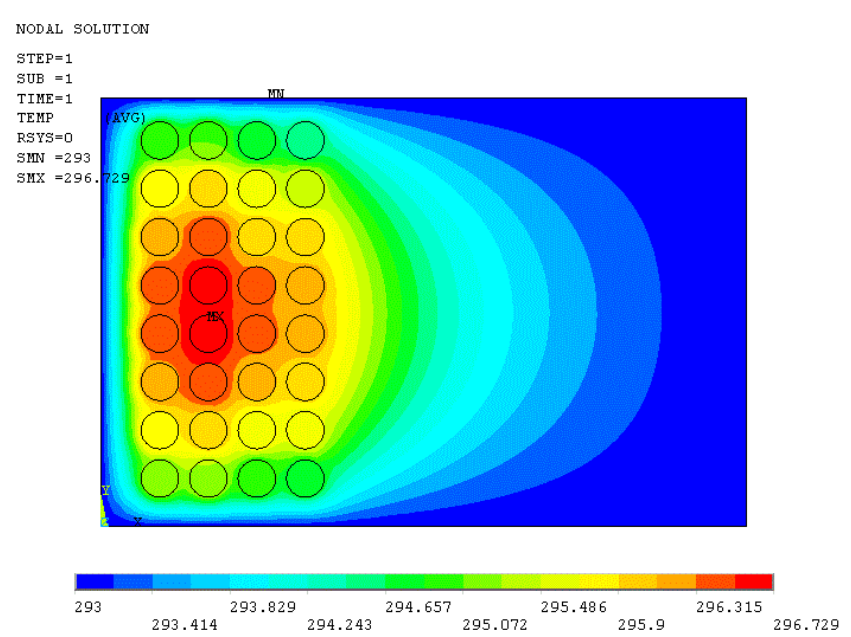

Fig. 6. A model for temperature distribution over a microplate in the experiment 1. All horizontal rows of wells one by one are filled as provided by the Fig. 5 schemes.

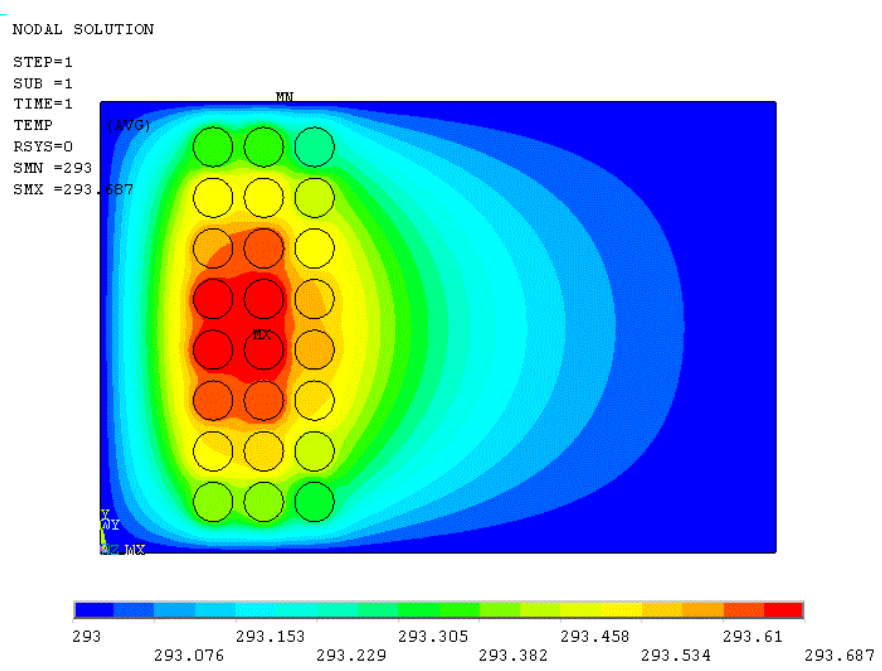

Fig. 7. A model for temperature distribution over a microplate in the experiment 2. All horizontal rows of wells one by one are filled as provided by the Fig. 5 schemes.

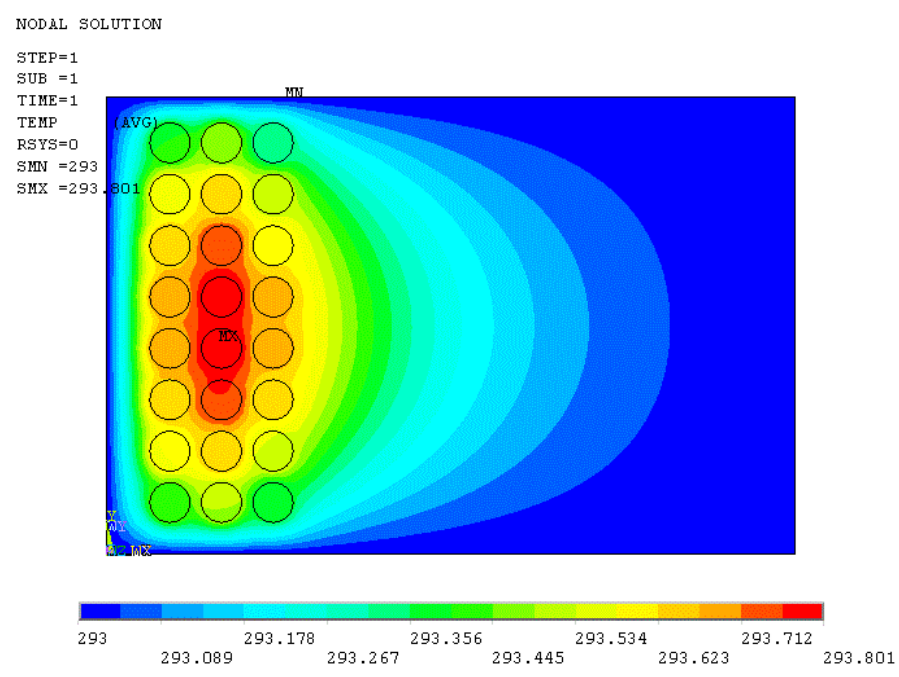

Fig. 8. A model for temperature distribution over a microplate in the experiment 3. All horizontal rows of wells one by one are filled as provided by the Fig. 5 schemes. 
The theoretical and experimental temperature means are compared in the Table 4. A strong $(\mathrm{R}=1.00, p=0.04)$ correlation between experimental and mathematically calculated thermodynamic parameters of weak heat sources associated with bacterial adhesion was detected.

Table 4. Temperature differences obtained from the experimental data $(\Delta T)$ and numerical simulation $\left(\Delta T^{\prime}\right)$.

\begin{tabular}{|c|l|c|}
\hline Experiment number & $\Delta T$ & $\Delta T^{\prime}$ \\
\hline 1 & 3.7 & 3.729 \\
\hline 2 & 0.4 & 0.687 \\
\hline 3 & 0.3 & 0.801 \\
\hline
\end{tabular}

\section{Conclusion}

As a result of experimental and theoretical studies, it is established that the method of infrared thermography can be successfully used for evaluation of the power of weak heat sources associated with bacterial adhesion. The experimental setup was designed and theoretical basis for studies on heat flow generated by bacterial adhesion using thermal imaging techniques was developed. The infrared thermography method was successfully tested at the estimation of total heat generated by chemical compound dissolution and adhesion of Rhodococcus cells to polystyrene microplates. In addition, a mathematical model for heat flow at bacterial adhesion was obtained.

\section{Acknowledgments}

The research was partly supported by the Ministry of Education and Science of Russian Federation (grant GK 16.518.11.7069), Russian fund for basic research (grant RFBR 11-04-96045-r_ural_a), Grant of president of Russian Federation for young researchers (MD-2684.2012.1).

\section{REFERENCES}

[1] Digel, I. Controlling Microbial Adhesion: A Surface Engineering Approach / I. Digel // In: Bioengineering in Cell and Tissue Research, edited by Artmann G.M., Chien S. - Leipzig: Springer-Verlag, 2008. - P. 601-623.

[2] Hori, K. Bacterial Adhesion: from Mechanism to Control / K. Hori, S. Matsumoto // Biochemical Engineering Journal. - 2010. - Vol. 48. - P. 424-434.

[3] Carnazza, S. New Advances in Cell Adhesion Technology / S. Carnazza // In: Nanoparticles and Nanodevices in Biological Applications, edited by Belucci S. - Leipzig: Springer-Verlag, 2009. - P. 69-130.

[4] Bayoudh, S. Assessing Bacterial Adhesion Using DLVO and XDLVO Theories and the Jet Impingement Technique / S. Bayoudh, A. Othmane, L. Morac, H.B. Ouada // Colloids and Surfaces B: Biointerfaces. - 2009. Vol. 73. - P. 1-9.

[5] Ivshina, I. B. Bacteria of the genus Rhodococcus (immunodiagnosis, detection, biodiversity): abstract of. thesis ... Dr. biol. Science /Ivshina I. B. - Perm, 1997. - 197 p.

[6] Philp, J.C. Alkanotrophic Rhodococcus ruber as a biosurfactant producer / J.C. Philp, M.S. Kuyukina, I.B. Ivshina et al. // Applied Microbiology and Biotechnology. - 2002. - Vol. 59. - P. 318-324.

[7] Kuyukina, M.S. Application of Rhodococcus in bioremediation of contaminated environments / M.S. Kuyukina, I.B. Ivshina // In: Microbiology Monographs, edited by Steinbuchel A. Berlin: Springer-Verlag, 2010. - Vol. 16. P. 231-262.

[8] Dawson, R. Directory of biochemist. R. Dawson, D. Elliott, W. Elliott, and K. Jones - M.: World, $1991 .-544$ p.

[9] Huber, B. The cep quorum-sensing system of Burkholderia cepacia H111 controls biofilm formation and swarming motility / B. Huber, K. Riedel, M. Hentzer et al. // Microbiology. - 2001. - Vol. 147. - P. 2517-2528.

[10] Abakumov, N. A. Inorganic chemistry: tutorial / N. A. Abakumov, N.N. Bikov. - Tambov: Tambov. State. Technical. Univ, 2009. - 124 p.

[11] Kuyukina, M.S. Recovery of Rhodococcus biosurfactants using methyl tertiary-butyl ether extraction / M.S. Kuyukina, I.B. Ivshina, J.C. Philp et al. // Journal of Microbiological Methods. - 2001. - Vol. 46, No. 2. - P. 149156.

[12] Shalumov, A. S. Introduction to ANSYS: Strength and thermal analysis. Tutorial / A. S. Shalumov, A. S. Vachenko, O. A. Fadeev, D. B. Bagaev. - Kovrov: KSTA, 2002. - 33 p. 